\title{
Analysis and Countermeasure of Private Enterprises Wastage Yu-Qing $\mathrm{HONG}^{1, \mathrm{a},{ }^{*}}$ \\ ${ }^{1}$ School of Business Administration, Zhejiang Gongshang University, Hangzhou, China a470202425@qq.com \\ ${ }^{*}$ Corresponding author
}

Keywords: private enterprise, talent drain, investigation, analysis, coping mechanisms

\begin{abstract}
Talents are the cornerstones of the development of modern enterprises. However, the loss of talents of China's private enterprises is quite serious, talent drain has become a hot focus of private economy in recent years. Based on the local private enterprises in the writer's city, we make the research of the talent drain by adopting the method of questionnaire, the data from the questionnaires were analyzed on the basis of the data, and put forward corresponding countermeasures that only companies recognize the importance of talent, take the "treatment - cause emotion" three-in-one strategy to attract talent, to enhance the vitality and competitiveness of private enterprises.
\end{abstract}

\section{Introduction}

Private enterprise is the important force to promote Chinese economic growth and the strong opponent of monopolistic competition having the important status in the national economy of our country. But in recent years, the loss of a large number of talents has become an important factor restricting the development of private enterprises. French scholar Jean - Baptist Meyer studies show that high-quality talent (scientists, engineers, etc.), is the comparison between countries have serious problems. With the development of globalization, the economic growth of high quality talents with the dependence of the science and technology to enhance, this makes the brain drain problem is getting more and more apparent[1]. Private enterprises, the vulnerable groups in social competition, should be fully aware of their own shortcomings and to take corresponding countermeasures, to remain invincible in the fierce competition in the market.

\section{Present situation of private enterprise talent drain}

(a). High rate of the talent drain: The flow of talent in the enterprise is normal, but awareness of this phenomenon is needed. According to the statistics, the rate of talent loss of good corporate rate should be about $15 \%$, but it turns out to be $50 \%$ in our country. High personnel turnover rate leads to the waste of enterprise human resources cost, increasing economic pressure and the risk of commercial secret leaking; At the same time,it can also produce exemplary role for other employees, which can cause the heart instability. In addition, the loss of qualified teachers in enterprises is also easy to cause bad influence to the enterprise image.

(b) the high frequency flow of talent. Usually, the people who work in private enterprises a two or three years will change the service object. As a result, the life of private enterprises in our country is very short, only 2.9 years on average.

(c) private enterprises urgently demand for talent, especially those core personnel likes high-level management personnel and professional and technical personnel have become the object of numerous companies scramble to chase. At the same time, in order to pursue benefit maximization, talents will constantly to well-known enterprises. 


\section{Reasons for the loss of private enterprise talent}

Japanese scholars Yoshirou Nakamatu mentioned in his book Interpersonal relationship equation, in the whole social environment, to maximize the overall function, the individual's ability to get sufficient play, so the development direction of the individual and the whole must have consistency[2].When the development direction of the development direction of the individual and the overall conflict. On the one hand it is individual to ensure that the overall interests, take the initiative to change the individual itself development goals, to the development of the overall direction, Leading the unity of individual and overall interests; on the other hand it is to the individual to find new work environment to meet the personal goal, it will produce a brain drain ${ }^{[3]}$.In order to well understand the root cause of talent outflow in private enterprises, the author designs the corresponding questionnaire. Based on the specific data analysis and combined with the expansion of the Mowbray model content, try to capture all kinds of complex factors for the talent outflow as much as possible. Although single study cannot be the inclusive and comprehensive solution to this problem, the designer of expansion Mowbray model method to combine multiple variables of employee outflow (such as corporate, environmental and individual) and construct a more comprehensive and complete theoretical model for the employees outflow (Figure 1-1).

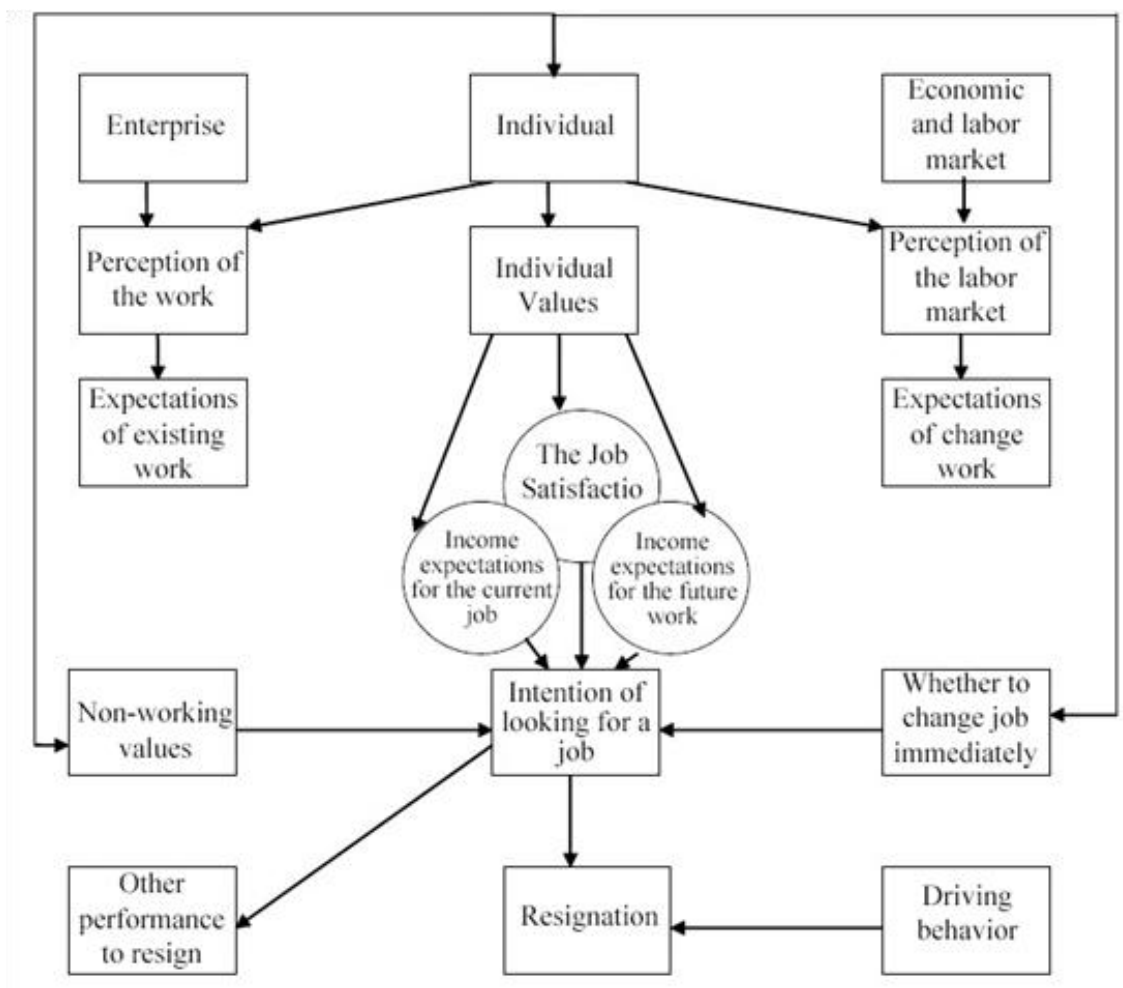

Figure 1-1

Muchinsky\&Tuttle, Woturba scholars, think a lot of investigation and study, from the perspective of individual analysis, before the people to find a job, the work will be have a space to work environment, development condition such as expected, people after working, the work of the actual situation and the closer the expected environment, personal satisfaction is higher, the smaller the possibility of a departure ${ }^{[4]}$.Expansion Mowbray model indicates that the talent outflow mainly consists of four basic factors: (1) job satisfaction; (2) the expectation for changing the job roles and the relevant earning within the enterprise; (3) the expectation for changing the job roles and the relevant earning within the enterprise; (4) non-work values and causal factors, namely lifestyle, 
religion and so on.

Make the survey statistics based on the results of the questionnaire; the corresponding statistics are as follows:

(1) The proportion of respondents' education statistics was shown in Figure 2-2

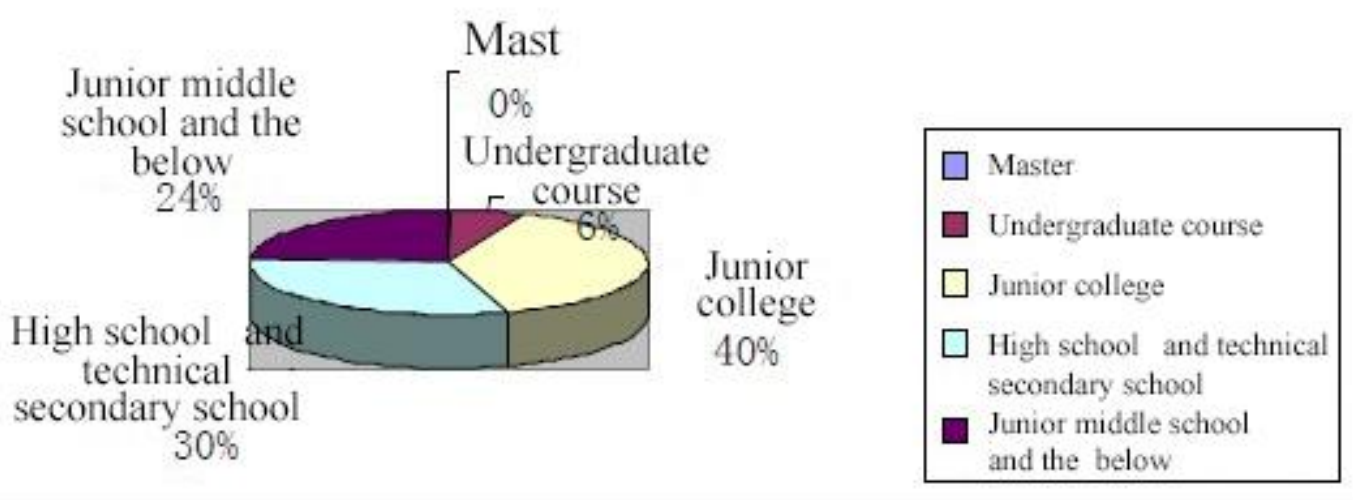

Figure 2-2

(2) The proportion of respondents' ages statistics was shown in Figure 2-3
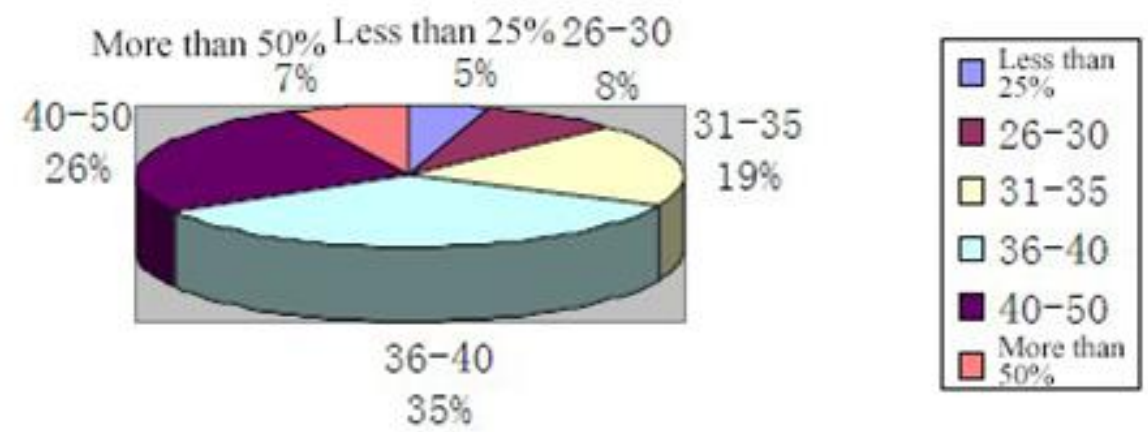

Figure 2-3

(3) The flow direction of respondents' dimission statistics was shown in Figure 2-4

\begin{tabular}{|l|l|l|l|l|l|}
\hline $\begin{array}{l}\text { Whereabo } \\
\text { uts }\end{array}$ & $\begin{array}{l}\text { Foreign } \\
\text { companies }\end{array}$ & $\begin{array}{l}\text { Continue to } \\
\text { learn }\end{array}$ & $\begin{array}{l}\text { Intend to go } \\
\text { abroad }\end{array}$ & Civil & $\begin{array}{l}\text { Other } \\
\text { companies }\end{array}$ \\
\hline Number & 27 & 6 & 1 & 8 & 12 \\
\hline
\end{tabular}

Figure 2-4

(4) Reasons for respondents' leaving was shown in Figure 2-5 

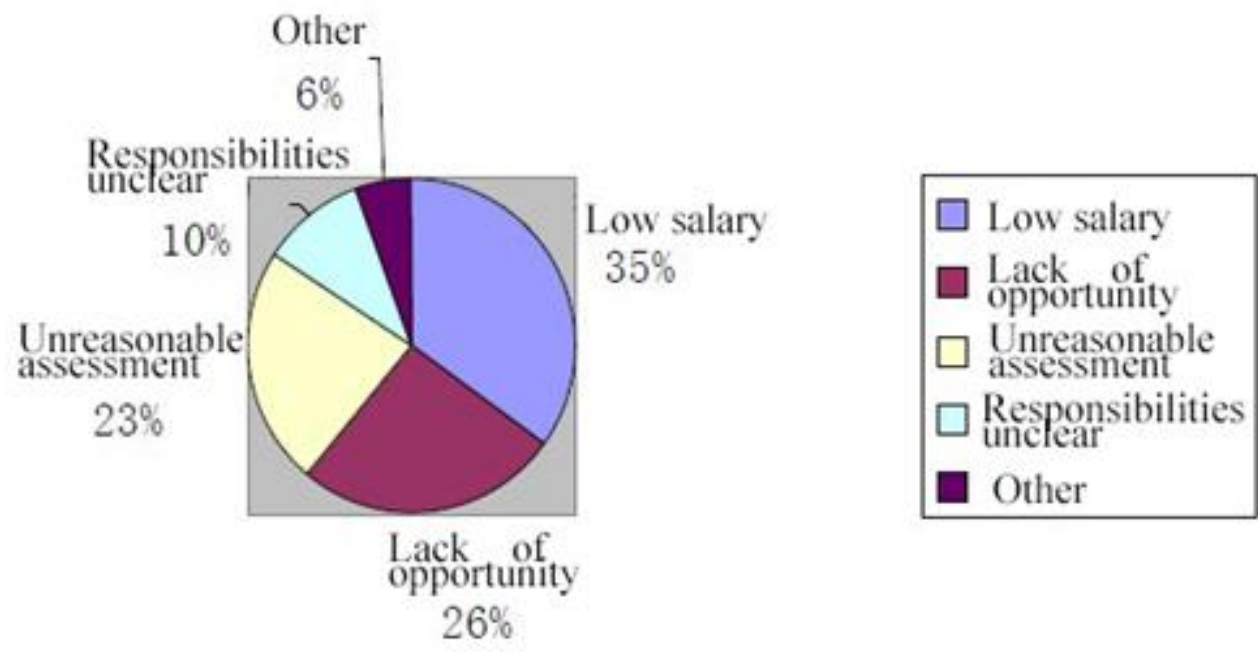

Figure 2-5

(5) Reasons for respondents choosing a new company was shown in Figure 2-6

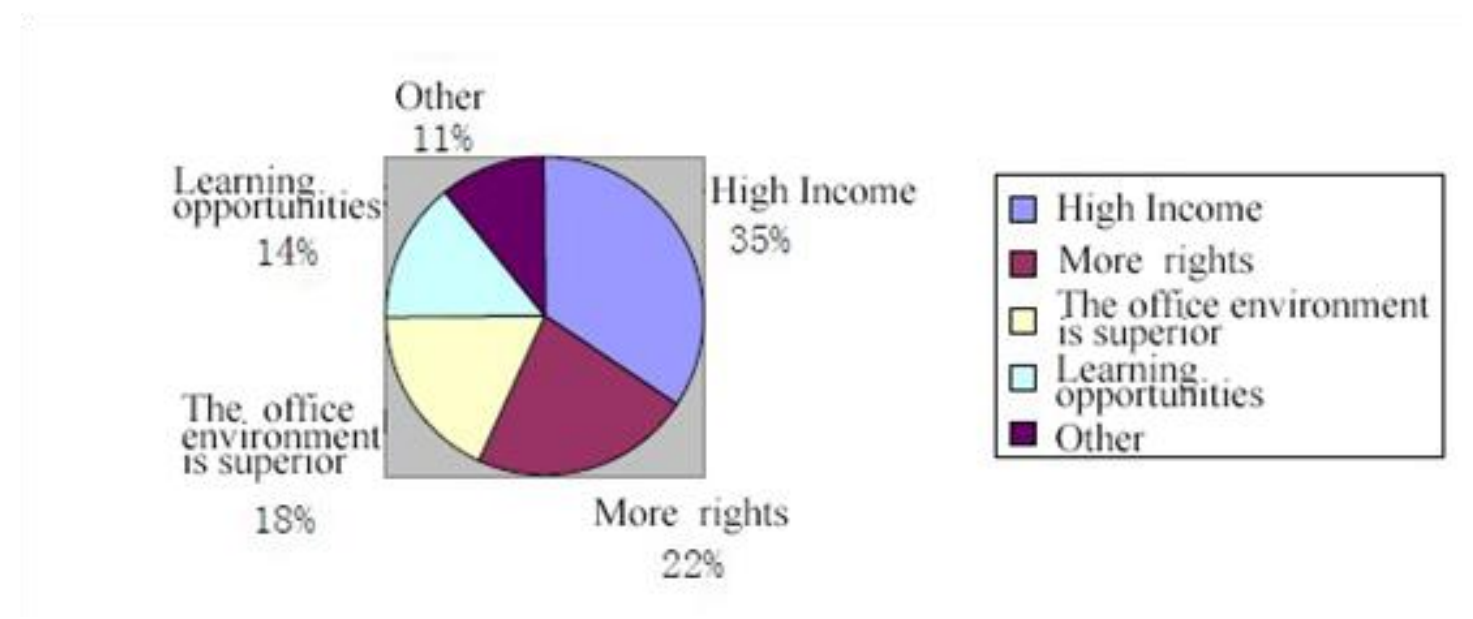

Figure 2-6

By a random survey of separating employee in private enterprises, combine the expansion Mowbray model and analyze corresponding data, we can see that the main reason for talent outflow are as follows:

(a) Inadequate space for development: China's private enterprises are mostly family businesses, operators are not so confident with outsiders; it is difficult for them to give important parts to employees for management. Since talents think the development space is not comply with individuals planning, the idea for finding another good job is easy to produce.

(b) Investment for nurturing talents is too poor: there is a characteristic for private enterprises to use personals: low input and high output. On the one hand, China's private enterprises has weak awareness to train staff, they focus only on economic profit and cost control; on the other hand, based on the large amount of talent outflow and high loss rates, enterprises are afraid of developing talent which result in a vicious cycle. Talents will generate dissatisfaction and leave because companies cannot meet their individual needs to enhance the quality.

(c) Treatment discontent: the work intensity of employees in private enterprises is large, serious 
overtime working hours and instability result in ultra-labor intensity which have some of damage on the physical and psychological healthy. However, in the contract, talents not always get the corresponding reward.

(d) The lack of a cohesive enterprises culture: enterprises culture can inspire employees' the sense of mission, strengthen the sense of responsibility, give the sense of honor sense of honor as well as give a sense of belonging to employees. Most private companies do not focus on building enterprises culture, there is no internal cohesion. Many talents have no dissatisfaction for material and other aspect, but do not have much affection for the enterprise, and they are easy to quit.

\section{Private Enterprise Strategies brain drain}

Huge loss of talents in private enterprise is because operators do not establish a complete talent mechanism to retain talents. So if private enterprise want to get a good development, it is necessary to build the trinity mechanisms of "treatment - career - affection" to deal with the loss of talents.

(a) Treatment Retention

Physiological needs of survival are the basic need of Maslow's hierarchy, while the treatment provided is the economy basis for staffs to meet the physical needs.

Reasonable treatment mechanisms include remuneration mechanisms and welfare system. When design salary system, the principle of distributing according to work, giving priority to efficiency priority efficiency, take count of equity simultaneously and other sustainable developments shall be take into consideration. In the long term, the salary may have relation with the enterprises profit and permit core talent to buy the share and become benefit community. Welfare and security system have to be developed in accordance with national regulations, including pension, unemployment, medical care and other basic welfare system, let talents feel safety and also play a role in motivation.

(b) Career Retention

The modern concept of talent management requires respecting talents, not only to recruit and retain qualified personals, but also develop their own talents. Therefore, career retention shall firstly pay attention to the talents' career planning, together to create a better business vision according to the long-term development strategy for the enterprise and the individual needs to develop talents. For family businesses, it should seek corporate restructuring, management and ownership separation to make the senior officers get promotion opportunities.

For general staff, give them the opportunity to become a useful person and establish training mechanism. Self-trained talent will have higher corporate loyalty and it is not easily to lose.

(c) Affection Retention

After the treatment and career has been met, the affection feeling will be focused. So, affection retention is the key to retaining talents, and also the most advanced means of keeping talents.

Affection retention can be divided in two sides: 1.Play the role of a leader. The care from leaders to subordinates can have a greater incentive; the personal charisma can also play a unifying role. 2 . Focus on the role of enterprises culture. Enterprises culture is a basic common belief and cognitive which is followed by organization members, it plays a great role in improving the cohesion and solidarity of the enterprises which will have hint in the thinking of employees to form a loyal implied.

The construction of enterprise culture is accumulated in a long time in the process of gradually mature, and have their own characteristics, but some cannot implement the corporate culture construction, only on the paper, the real in the practical work can not form the cultural construction of the system[5]. The construction of enterprise culture can make the employees' ideas and 
enterprise cultural values form the spiritual resonance, produce psychological identity, to love, and together with the enterprise. Construction of enterprises will have employees' spiritual resonance on the stuffs' thinking and the enterprises cultural values, and produce psychological sense of identity which lead to the love for enterprises and jointly advance and retreat with the enterprises.

\section{Acknowledgment}

This work has been supported by the Natural Science Foundation of China (Project No. 71002092), Zhejiang Provincial Natural Science Foundation Project of China (Project No. LQ13G020003), and Zhejiang Provincial Philosophy Social Science Planning Project of China (Project No. 13NDJC047YB, 12JCGL14YB).

\section{References}

[1] Enshun T. Management of risks posed by human resource outsourcing[J]. Chinese Business Review, 2007, 6(45):55-58.

[2] Iverson R D. An event history analysis employee turnover the case of hospital employees in Australia[J]. Human resource management review, 1999(04):397-418.

[3] Price J L. The Study of Turnover[M]. Ames IA:Iowa State University Press, 1977:87-89.

[4] Griffeth,W Hom,Gaertner.Ameta-analysis of antecedents and correlates of employee tumovcr:update,moderator tests,and research implication for the next millennium[J].Journal of Management,2000,(03):463-488.

[5] Price ,J.L.2001. Reflections on the determinants of voluntary turnover Journal of International Manpower.22:600 624. 